\title{
Transcriptomic analysis of sea cucumber (Holothuria leucospilota) coelomocytes revealed the echinoderm cytokine response during immune challenge
}

Xiaofen $\mathrm{Wu}^{1,2 \dagger}$, Ting Chen ${ }^{1,3 \dagger}$, Da Huo ${ }^{1,3,4}$, Zonghe Yu ${ }^{1,3,4}$, Yao Ruan ${ }^{1,2}$, Chuhang Cheng ${ }^{1,2}$, Xiao Jiang ${ }^{1,3,4}$ and Chunhua Ren ${ }^{1,3,4^{*}}$

\begin{abstract}
Background: The sea cucumber Holothuria leucospilota belongs to echinoderm, which is evolutionally the most primitive group of deuterostomes. Sea cucumber has a cavity between its digestive tract and the body wall that is filled with fluid and suspended coelomic cells similar to blood cells. The humoral immune response of the sea cucumber is based on the secretion of various immune factors from coelomocytes into the coelomic cavity. The aim of this study is to lay out a foundation for the immune mechanisms in echinoderms and their origins in chordates by using RNA-seq.

Results: Sea cucumber primary coelomocytes were isolated from healthy $\mathrm{H}$. leucospilota and incubated with lipopolysaccharide (LPS, $10 \mu \mathrm{g} / \mathrm{ml}$ ), polyinosinic-polycytidylic acid [Poly (l:C), $10 \mu \mathrm{g} / \mathrm{ml}$ ] and heat-inactived Vibrio harveyi $\left(10^{7}\right.$ cell/ml) for $24 \mathrm{~h}$, respectively. After high-throughput mRNA sequencing on an Illumina HiSeq2500, a de novo transcriptome was assembled and the Unigenes were annotated. Thirteen differentially expressed genes (DEGs) were selected randomly from our data and subsequently verified by using RT-qPCR. The results of RT-qPCR were consistent with those of the RNA-seq $\left(R^{2}=0.61\right)$. The top 10 significantly enriched signaling pathways and immune-related pathways of the common and unique DEGs were screened from the transcriptome data. Twentyone cytokine candidate DEGs were identified, which belong to 4 cytokine families, namely, BCL/CLL, EPRF1, IL-17 and TSP/TPO. Gene expression in response to LPS dose-increased treatment $(0,10,20$ and $50 \mu \mathrm{g} / \mathrm{ml})$ showed that IL-17 family cytokines were significantly upregulated after $10 \mu \mathrm{g} / \mathrm{ml}$ LPS challenge for $24 \mathrm{~h}$.

(Continued on next page)
\end{abstract}

\footnotetext{
* Correspondence: rosemary166@sina.com

${ }^{+}$Xiaofen Wu and Ting Chen contributed equally to this work.

'CAS Key Laboratory of Tropical Marine Bio-resources and Ecology (LMB), Guangdong Provincial Key Laboratory of Applied Marine Biology (LAMB), South China Sea Institute of Oceanology, Chinese Academy of Sciences, Guangzhou 510301, PR China

${ }^{3}$ Institution of South China Sea Ecology and Environmental Engineering, Chinese Academy of Sciences, ISEE, CAS, Guangzhou, PR China

Full list of author information is available at the end of the article
}

(c) The Author(s). 2020 Open Access This article is licensed under a Creative Commons Attribution 4.0 International License, which permits use, sharing, adaptation, distribution and reproduction in any medium or format, as long as you give appropriate credit to the original author(s) and the source, provide a link to the Creative Commons licence, and indicate if changes were made. The images or other third party material in this article are included in the article's Creative Commons licence, unless indicated otherwise in a credit line to the material. If material is not included in the article's Creative Commons licence and your intended use is not permitted by statutory regulation or exceeds the permitted use, you will need to obtain permission directly from the copyright holder. To view a copy of this licence, visit http://creativecommons.org/licenses/by/4.0/ The Creative Commons Public Domain Dedication waiver (http://creativecommons.org/publicdomain/zero/1.0/) applies to the data made available in this article, unless otherwise stated in a credit line to the data. 


\begin{abstract}
(Continued from previous page)
Conclusion: A de novo transcriptome was sequenced and assembled to generate the gene expression profiling across the sea cucumber coelomocytes treated with LPS, Poly $(I: C)$ and $V$. harveyi. The cytokine genes identified in DEGs could be classified into 4 cytokine families, in which the expression of IL-17 family cytokines was most significantly induced after $10 \mu \mathrm{g} / \mathrm{ml}$ LPS challenge for $24 \mathrm{~h}$. Our findings have laid the foundation not only for the research of molecular mechanisms related to the immune response in echinoderms but also for their origins in chordates, particularly in higher vertebrates.
\end{abstract}

Keywords: Sea cucumber, Coelomocytes, Transcriptome, RNA-seq, Differentailly expressed genes, Immune response, Cytokines

\section{Background}

Holothuria leucospilota is a tropical sea cucumber that belongs to phylum Echinodermata, class Holothuroidea, order Aspidochirotida and family Holothuriidae. Naturally, H. leucospilota is distributed in the Indo-West Pacific, mostly from eastern Africa to the Hawaii islands and Society islands in the Pacific ocean, and from southern Japan to the Sark bay in Australia [1]. In recent years, $H$. leucospilota has become an emerging aquaculture species in southern China [2]. Evolutionally, echinoderms are positioned taxonomically at the base of deuterostomes, along with the higher-order hemichordate and chordate groups [3]. Therefore, studies on the biological processes in echinoderms, such as development, reproduction, metabolism and immunity, may provide new insights not only for echinoderms themselves, but also for the origins of these biological processes in chordates, particularly in higher vertebrates.

Given that lacking of the adaptive immunity, the innate immunity is the major mechanism for sea cucumber to defend the environmental pathogens. The innate immunity of sea cucumber includes multiple immunerelated factors, such as, antimicrobial peptides (e.g. lectins, lysozyme, clotting protein and complement) [4, 5], antimicrobial reactive oxygen species [6], pattern recognition receptors, apoptosis $[7,8]$ and immune cytokines [9]. Sea cucumber has a cavity between its digestive tract and body wall that is filled with coelomic fluid and suspended coelomocytes that are similar to the hematocyts of vertebrates. In sea cucumber, the cellular immunity is executed by coelomocytes, and the humoral immunity is based on a variety of macromolecules in the coelomic cavity that secreted by coelomocytes [10-12]. When sea cucumbers are infected by pathogenic microbes, they rely on their cellular and humoral immune responses to identify and eliminate the invading microbes and repair the wounds [9].

Next-generation sequencing (NGS) technology is a revolutionary change to traditional sequencing technology. The high-throughput mRNA sequencing (RNA-seq) is a transcriptomic research method that provides information on transcript expression and has the advantages of being easy-handle and low-cost [13]. For non-model organisms, RNA-Seq is not limited to detecting transcripts that correspond to existing genomic sequence. RNA-Seq focus more on the coding region of genes and has very low background signal [14]. Therefore, RNASeq is particularly attractive for non-model organisms with genomic sequences that are yet to be determined.

To date, transcriptomic sequencing technology has been widely applied for analyzing the gene expression profiles of echinoderms in a variety of developmental and physiological processes, and under multiple infected- or stressed-conditions. In the sea urchin Heliocidaris erythrogramma, RNA-seq has been used to measure the mRNA expression profiles of larvae, metamorphism and post-metamorphism life cycle stages, to elucidate the evolutional and developmental mechanism of the radial adult body in echinoderms [15]. The expression dynamics across development has also been measured by RNA-seq in three sea urchin species: the lecithotroph $H$. erythrogramma, the closely related planktotroph $H$. tuberculata, and an outgroup planktotroph Lytechinus variegatus, to reveal how evolutionary changes in gene regulation contribute to phenotypic differences between different species [16]. In addition, RNA-seq has been used to analyze the differentially expressed genes (DEGs) in the body cavity cells between the viral-infected and normal starfish Pycnopodia helianthoides, to illustrate the immune and nervous responses to the sea star wasting disease [17]. Furthermore, the next-generation transcriptome data from 42 echinoderm specimens from 24 orders, 37 families have been collected to establish a web-based application (http://echinotol.org) to identify orthologs suitable for phylogenetic analysis in assembling the echinoderm tree of life [18].

In sea cucumber, transcriptomic sequencing has been performed together with genomic and proteomic analyses in Apostichopus japonicus, to facilitate the molecular underpinnings of visceral regeneration [19]. RNA-seq has been applied independently to analyze the DEGs between normal and regenerating radial nerve cord in Holothuria glaberrima, and revealed the key roles of 
extracellular matrix (ECM) remodeling and ECM-cell interactions in regeneration [20]. In addition, the applications of transcriptomic analyses in sea cucumber include identification of long noncoding RNA species [21], illustration of the mechanisms of aestivation [22], abnormal development [23], and body wall pigmentation [24]. Moreover, immune-related genes in the A. japonicus coelomocytes under Vibrio splendidus challenge have been identified, which are clustered into the immune pathways of endocytosis, lysosome, chemokine, and MAPK and ERBB signaling [25]. However, there is still limited research reports on the species and response of the cytokines secreted by coelomocytes of sea cucumber under challenge of immune stimuli.

In this study, high-throughput transcriptomic sequencing and bioinformatics analysis were performed on the primary coelomocytes isolated from the sea cucumber H. leucospilota and treated with three different immune stimuli including lipopolysaccharide (LPS), polyinosinicpolycytidylic acid [poly (I:C)] and heat-inactived Vibrio harveyi for $24 \mathrm{~h}$. Based on the DEGs between different groups, the immune-related pathways were screened out and the responded cytokines were identified. This study provides evidences for the potential roles of cytokines in the innate immunity of sea cucumber.

\section{Results}

\section{Illumina draft reads and sequence assembly}

Primary coelomocytes isolated from the sea cucumber $H$. leucospilota were respectively challenged with LPS, poly (I:C) and heat-inactivated $V$. harveyi for $24 \mathrm{~h}$ (Fig. 1a), and twelve cDNA libraries were constructed to perform Illumina sequencing. After assembly and redundancy removal, a transcriptome with twelve RNA-seq libraries in total of $6.69 \mathrm{~GB}$ with 73,472 identified Unigenes was obtained and submitted to GenBank under the BioProject accession No. PRJNA559679. The total length, average length, N50, and GC content of the Unigenes were 47,163, $631 \mathrm{bp}, 641 \mathrm{bp}, 1015 \mathrm{bp}$ and 39.54\%, respectively. The number of transcripts and Unigenes decreased with increasing of length, and the majority of them were concentrated in $200-3000$ bp (Fig. 1b). The Unigene sequences were annotated to seven functional databases, and 20,926 (28.48\%) of them were significantly matched to at least one of the databases (Table 1), in which 19,156 (26.07\%) to NR, 3990 (5.43\%) to NT, 14803 (20.15\%) to SwissProt, 13,615 (18.53\%) to KOG, 15277 (20.79\%) to KEGG, 7097 (9.66\%) to GO and 15,624 (21.27\%) to InterPro. The annotation results for five databases were further showed in a Venn diagram: 1584, 11, 88, 21 and 528 genes were independently annotated into the NR, KOG, KEGG, SwissProt and InterPro databases, respectively, and the intersection set of these five databases was 11,103 (Fig. 1c). For the NR database, the annotated Unigenes were majorly matched to Strongylocentrotus purpuratus (5552, 28.98\%), Acanthaster planci (6117, 31.93\%), Saccoglossus kowalevskii (883, 4.61\%), Branchiostoma belcheri (457, 2.39\%) and other species $(6147,32.09 \%$, Fig. 1d).

\section{Analysis of DEGs and validation of RNA-Seq data by RT- qPCR}

The transcriptomic data obtained from the control group (CT), LPS-treatment group (LPS), Poly (I:C)-treatment group (PIC) and $V$. harveyi-treatment group (VH) were analyzed comparatively. The results showed that the co-expressed DEGs for the three groups were 1180, and the uniquely-expressed genes in the LPS-vs-CT, PIC-vs-CT and VH-vs-CT groups were 3846, 3869 and 2279, respectively (Fig. 2a). The significantly DEGs were acquired by comparing of the gene expression between the LPS, PIC and VH groups and the CT group with the following criteria: $P \leq 0.01, \mid \log 2$-fold-change $\mid \geq 1$ and false discovery rate $(F D R) \leq 0.05$. Finally, 7074 DEGs in the LPS-vs-CT comparison (666 upregulated and 6408 downregulated), 7737 DEGs in the PIC-vs-CT comparison (355 upregulated and 7382 downregulated), and 5481 DEGs in the VH-vs-CT comparison (387 upregulated and 5094 downregulated) were obtained (Fig. 2b).

To validate the gene expression results of the RNA-seq data, 13 significant DEGs from the LPS-vs-CT comparison with the criteria of $P<0.01$, FDR $<0.05$ and fold change of at least 4 were selected for RT-qPCR validation. The volcano plot for the CT-vs-LSP comparison was shown in Fig. 2c. The expression levels of the selected 13 genes in the LPS challenge group were normalized to the control group. As anticipated, the RT-qPCR data showed a positive linear relationship with the RNA-Seq data (Fig. 2d), and there was no statistically significant difference between the two datasets $(P>0.05)$. This result suggested that the RNA-Seq was a positively related reference for expression profiling study on the whole, and the assembly quality of the sequences was desirable.

\section{Functional classification and enrichment analysis of GO terms and KEGG pathways for co-expressed DEGs}

The co-expressed DEGs after the three different immune challenges may represent the essential genes for immune defense in sea cucumber. GO (gene ontology) is a major bioinformatics initiative to unify the classification of genes and gene product attributes across all species. Among the total 1180 co-expressed DEGs, 796 were annotated with GO terms, in which 321 were annotated as "biological process", 279 were annotated as "cellular components" and 196 were annotated as "molecular functions" (Fig. 3a).

KEGG (Kyoto Encyclopedia of Genes and Genomes) is a reference database dealing with genomes, biological pathways, diseases, drugs, and chemical substances. In 


\section{A}

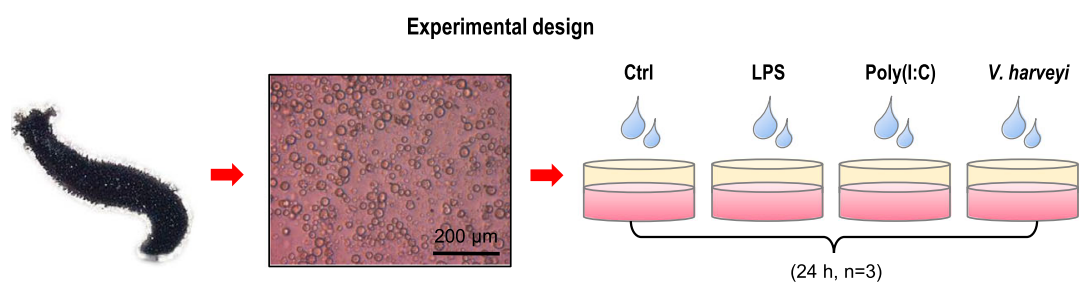

B

Length of distribution of Mix-Unigenes/transcripts

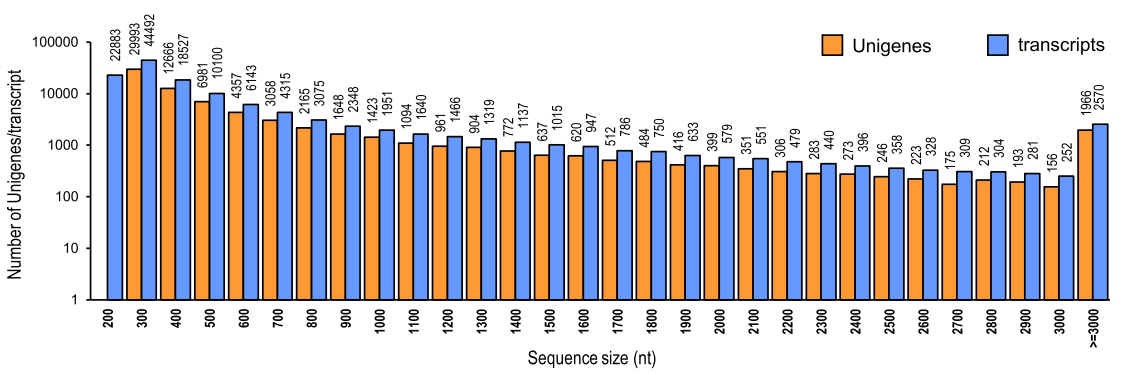

C

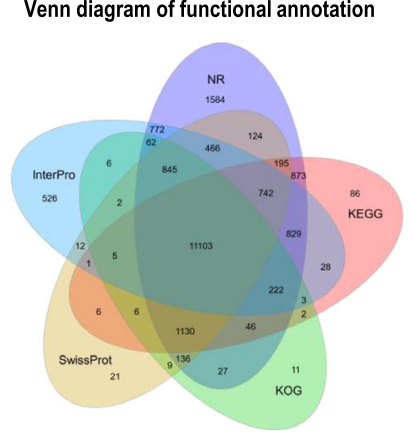

D Species distribution

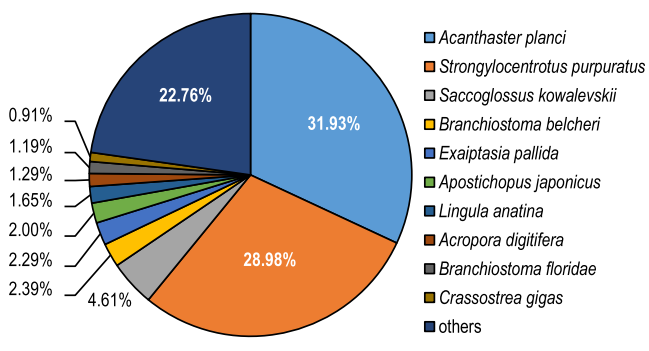

Fig. 1 Experimental design and transcriptome information. a Experimental design. Sea cucumber coelomocytes isolated from $\mathrm{H}$. leucospilota were challenged with LPS $(10 \mu \mathrm{g} / \mathrm{ml})$, Poly $(\mathrm{l}: \mathrm{C})(10 \mu \mathrm{g} / \mathrm{ml})$ and V.harveyi $\left(10^{7}\right.$ cell/ml) for $24 \mathrm{~h}$ with three biological duplicates. $\mathbf{b}$ The length distribution of all-Unigene. The $\mathrm{X}$-axis represents the sequence size, and the $\mathrm{Y}$-axis represents the number of Mix-Unigene. The orange bar shows the number of unigene which is the representative sequences, and the blue bar shows the number of transcripts which include the rough sequences. $\mathbf{c}$ Venn diagram of Unigene annotation. The databases used for gene annotation include NR、KOG、KEGG、SwissProt and InterPro. d Species distribution of Unigene annotation in NR database

this case, 1003 co-expressed DEGs were annotated in KEGG, and the number of DEGs in cellular processes, environmental information processing, genetic information processing, human diseases, metabolism and organismal systems categories were 123, 113, 20, 344, 161 and 242, respectively (Fig. 3b).

Gene set enrichment analysis (GSEA, also called functional enrichment analysis) is a method to identify classes of genes or proteins that are overrepresented in a large set of genes or proteins and [26]. The co-expressed DEGs in this study were annotated into 273 KEGG pathways. The top 10 and top 20 significantly enriched pathways were shown in Table 2 and Fig. 3c, respectively. The pathways of Staphylococcus aureus infection, complement and coagulation cascades, and tubercuosis were the three most significantly enriched pathways, with a total of 15, 16 and 24 co-expressed DEGs annotation, respectively (Table 2). In addition, the top 10 immunerelated KEGG pathways with the highest number of co-

Table 1 Functional annotation analysis

\begin{tabular}{|c|c|c|c|c|c|c|c|c|c|c|}
\hline & Total & NR & NT & SwissPprot & KEGG & KOG & InterPro & GO & Intersection & Overall \\
\hline No. of gene & 73,472 & 19,156 & 3990 & 14,803 & 15,277 & 13,615 & 15,624 & 7097 & 1285 & 20,926 \\
\hline Percentage & $100 \%$ & $26.07 \%$ & $5.43 \%$ & $20.15 \%$ & $20.79 \%$ & $18.53 \%$ & $21.27 \%$ & $9.66 \%$ & $1.75 \%$ & $28.48 \%$ \\
\hline
\end{tabular}



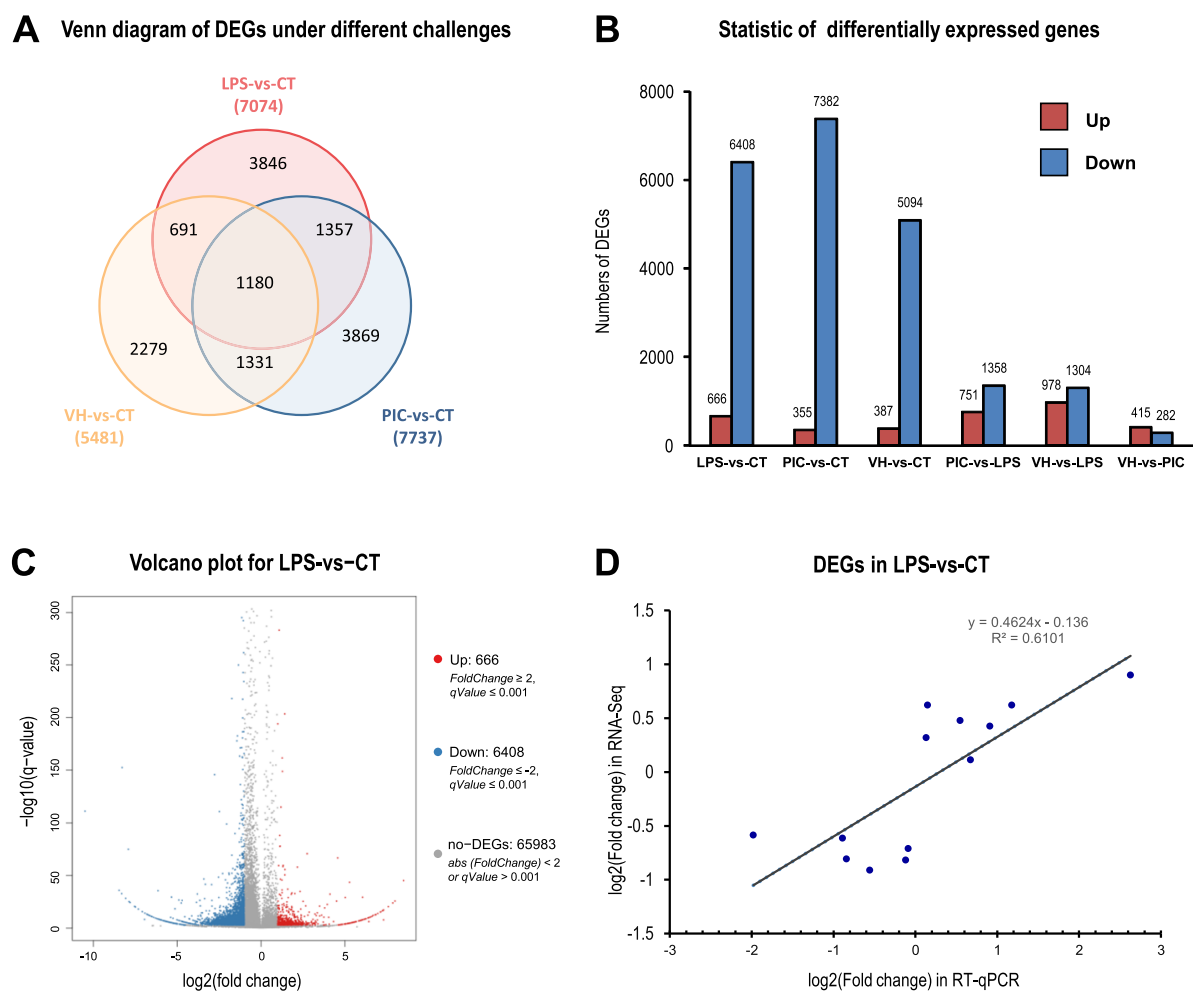

Fig. 2 Comparative transcriptome analysis of DEGs among different immune challenges. a Venn diagram of unique and common DEGs among the immune challenges of LPS、Poly (I:C) and $V$. harveyi. $\mathbf{b}$ the number of up- and down-regulated DEGs in each immune challenge group compared with control group (the first 3 combination bar) and the pairwise comparison of the three different immune challenge groups (the last 3 combination bar). $\mathbf{c}$ Volcano map of DEGs in LPS-vs-CT group: X-axis represents the fold change value after log2 conversion, and Y-axis represents the fold change after - $\log 10$ conversion. Red dots represent the up-regulated DEGs, blue dots represent the down-regulated DEGs, and gray dots represents the non-DEGs. $\mathbf{d}$ comparison results between RNA-Seq by RT-qPCR data in LPS-vs-CT group. X axis shows the fold changes of gene expression in RT-qPCR data, while $Y$ axis represents the fold changes of gene expression in RNA-Seq data

expressed genes were shown in Table 3. Within them, the most significant immune-related KEGG pathways were complement and coagulation cascades, which contained 84 annotated genes with 16 co-expressed DEGs. These results laid a foundation for discovering the immune-related genes and developing the immune responding mechanisms of sea cucumber. The functional classification and enrichment analysis of GO terms and KEGG pathways for the DEGs were further performed for the challenges of different immune stimuli (Fig. 3d). In this case, the totals of 2591, 3260 and 2585 Unigenes respectively for the comparisons of the LPSvs-CT, PIC-vs-CT and VH-vs-CT were annotated in GO terms. Among three different immune challenge groups, the Poly $(\mathrm{I}: \mathrm{C})$ treatment group had the most DEGs annotated into the GO terms, indicating that more genes were involved in the administration of Poly (I:C) in the sea cucumber coelomocytes when compared to other two immune stimuli.

\section{The most significant enrichment pathway of DEGs in different immune challenges}

A hypergeometric test was used for enrichment analysis of all signal pathways in the KEGG database. Compared to the control group, the number of DEGs annotated to specific pathways for the LPS, Poly (I:C) and $V$. harveyi treatment groups were 3415,4261 and 3120 , respectively. The top 10 most significantly enriched pathways for each challenge were shown in Table 4, in which the common pathways for the three treatments groups were the $A B C$ transporter pathway, ubiquitin-mediated proteolysis pathway and inositol phosphate metabolism pathway. The glucagon signaling pathway was a common pathway for the Poly (I:C) and $V$. harveyi treatment groups, and other pathways were specific for each treatment. Analysis of the DEGs enriched KEGG pathways provides an effective basis for studying the immune defense process, biological function and metabolic pathways in the sea cucumber coelomocytes.

\section{Analysis of immune-related pathway in different immune challenges}

Compared to the control group, the DEGs of the LPS, Poly (I: C) and $V$. harveyi treatment groups were categorized into 308, 316 and 305 annotated KEGG pathways, respectively. Accordingly, 18, 22 and 23 significantly enriched immune-related pathways for LPS, Poly (I: C) 


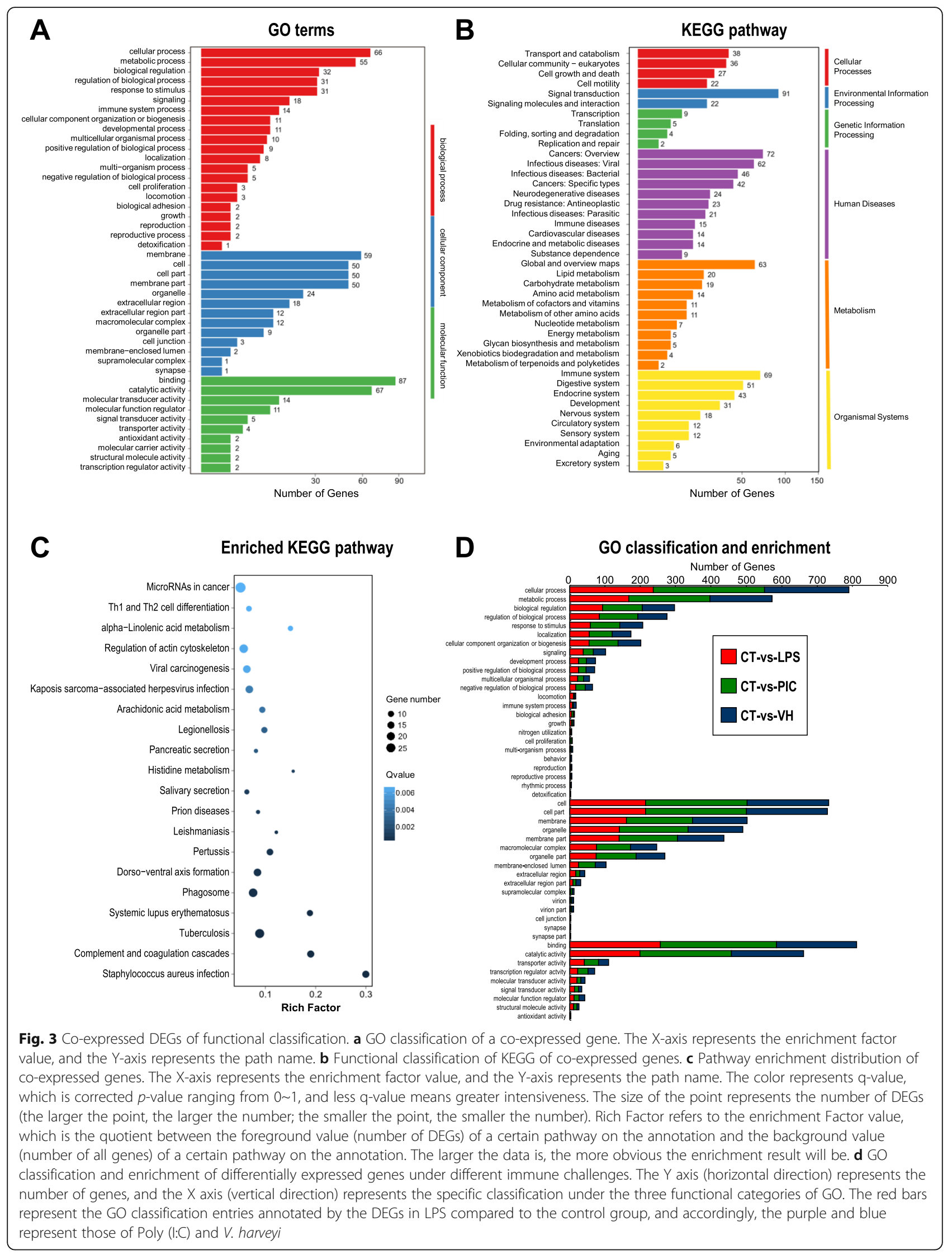


Table 2 The top 10 KEGG pathways with the highest enrichment of co-expressed DEGs

\begin{tabular}{|c|c|c|c|c|}
\hline Pathway ID & DEGs annotation in the pathway & All genes annotation in the pathway & $\boldsymbol{P}$-values & Pathway annotation \\
\hline ko05150 & $15(3.85 \%)$ & $50(0.33 \%)$ & $9.73403 e-13$ & Staphylococcus aureus infection \\
\hline ko04610 & $16(4.1 \%)$ & $84(0.55 \%)$ & $3.141596 \mathrm{e}-10$ & Complement and coagulation cascades \\
\hline ko05152 & $24(6.15 \%)$ & $271(1.77 \%)$ & $1.258897 \mathrm{e}-07$ & Tuberculosis \\
\hline ko05322 & $10(2.56 \%)$ & $53(0.35 \%)$ & $7.672128 \mathrm{e}-07$ & Systemic lupus erythematosus \\
\hline ko04145 & $22(5.64 \%)$ & $291(1.9 \%)$ & $5.889262 \mathrm{e}-06$ & Phagosome \\
\hline ko04320 & $18(4.62 \%)$ & $213(1.39 \%)$ & $9.237491 \mathrm{e}-06$ & Dorso-ventral axis formation \\
\hline ko05133 & $13(3.33 \%)$ & $119(0.78 \%)$ & $1.082585 e-05$ & Pertussis \\
\hline ko05140 & $11(2.82 \%)$ & $89(0.58 \%)$ & $1.597061 \mathrm{e}-05$ & Leishmaniasis \\
\hline ko05020 & $15(3.85 \%)$ & $172(1.13 \%)$ & $3.550144 \mathrm{e}-05$ & Prion diseases \\
\hline
\end{tabular}

and $V$. harveyi treatments, respectively, were identified according to the immune system of KEGG pathways. The most significantly enriched immune-related pathways for LPS, PIC and $V$. harveyi treatments were the Th1 and Th2 cell differentiation signaling pathways, the intestinal immune network for IgA production pathway, and the Fc gamma R-mediated phagocytosis pathway, respectively. Other top 10 significantly enriched immunerelated pathways for the three immune challenges are shown in Table 5. Base on the analysis of different regulatory pathways of the DEGs in KEGG, the mechanism of cellular immune response of the sea cucumber coelomocytes can be understood more directly.

\section{Identification of cytokines and their expression analysis after different challenges}

Cytokines are a broad and loose category of small proteins $(\sim 5-20 \mathrm{kDa})$ that are important for cell signaling, especially the immune signaling. Twenty-one cytokines were selected according to the NR database annotation of the transcriptomic data. The identified cytokines belong to four cytokine families, namely, the B-cell lymphokine (BCL/CLL), erythroid differentiation-related factor 1-like (EPRF1), interleukin 17-like (IL-17) and thrombospondin-like (TSP/TPO) families. In our transcriptome for the sea cucumber $H$. leucospilota, the BCL/CLL family included CCL11A, BCL3-X3, BCL10, CLL7A, CLL9-X3a, CLL9-X3b, CLL9-X3c, and CLL9$\mathrm{X} 3 \mathrm{~d}$; the EPRF1 family included EDRF1a, EDRF1b, EDRF1c, and EDRF1d; the IL-17 family included IL-17, IL-17-2, IL-17B, and IL-17C/E; and the TSP/TPO family included TPO-I-7A1-3, TPO-I-7B1-3, TSP-1a-c, and TSP-4. Among these cytokine families, the expression levels of the four genes in the interleukin-17 family after LPS challenge were significantly higher than those of other cytokines (Fig. 4), indicating that IL-17 was an important family of the cytokines in the immune response of sea cucumber, and its effective mechanism needs to be further investigated.

\section{Phylogenetic and structural domain analysis of the selected cytokines}

A phylogenetic tree was constructed using a maximumlikelihood (ML) method under MEGA7.0 with the deduced amino acid sequences from the selected cytokines, including BCL/CLL, EPRF1, IL-17 and the TSP/TPO family (Fig. 5a). The result showed that the cytokines were clustered into the corresponding branches.

The structural domains for some of the selected cytokines were predicted and shown in Fig. 5b. Specially, the

Table 3 The top 10 immune-related KEGG pathways with the highest number of co-expressed DEGs

\begin{tabular}{|c|c|c|c|c|}
\hline Pathway ID & DEGs annotation in the pathway & All genes annotation in the pathway & $\boldsymbol{P}$-values & Pathway annotation \\
\hline ko04610 & $16(4.1 \%)$ & $84(0.55 \%)$ & $3.141596 \mathrm{e}-10$ & Complement and coagulation cascades \\
\hline ko04658 & $15(3.85 \%)$ & $218(1.43 \%)$ & 0.0004926241 & Th1 and Th2 cell differentiation \\
\hline ko04650 & $7(1.79 \%)$ & $115(0.75 \%)$ & 0.02799556 & Natural killer cell mediated cytotoxicity \\
\hline ko04611 & $10(2.56 \%)$ & $213(1.39 \%)$ & 0.04710404 & Platelet activation \\
\hline ko04670 & $9(2.31 \%)$ & $208(1.36 \%)$ & 0.08609158 & Leukocyte transendothelial migration \\
\hline ko04666 & $7(1.79 \%)$ & $155(1.01 \%)$ & 0.102463 & Fc gamma R-mediated phagocytosis \\
\hline ko04620 & $5(1.28 \%)$ & $118(0.77 \%)$ & 0.1839742 & Toll-like receptor signaling pathway \\
\hline ko04659 & $4(1.03 \%)$ & $88(0.58 \%)$ & 0.1874437 & Th17 cell differentiation \\
\hline ko04062 & $7(1.79 \%)$ & $188(1.23 \%)$ & 0.2058452 & Chemokine signaling pathway \\
\hline ko04657 & $5(1.28 \%)$ & $127(0.83 \%)$ & 0.2245483 & IL-17 signaling pathway \\
\hline
\end{tabular}


Table 4 The top 10 KEGG pathways with the highest enrichment of DEGs in groups with different immune challenges

\begin{tabular}{|c|c|c|c|c|}
\hline Pathway ID & $\begin{array}{l}\text { DEGs annotation in the } \\
\text { pathway }\end{array}$ & $\begin{array}{l}\text { All genes annotation in the } \\
\text { pathway }\end{array}$ & $\boldsymbol{P}$-values & Pathway annotation \\
\hline \multicolumn{5}{|l|}{ CT-vs-LPS } \\
\hline ko02010 & $40(3.26 \%)$ & $163(1.07 \%)$ & $1.040587 e-10$ & $A B C$ transporters \\
\hline ko04120 & $41(3.34 \%)$ & $274(1.79 \%)$ & $7.710349 \mathrm{e}-05$ & Ubiquitin mediated proteolysis \\
\hline ko00250 & $15(1.22 \%)$ & $88(0.58 \%)$ & 0.004140363 & Alanine, aspartate and glutamate metabolism \\
\hline ko05215 & $21(1.71 \%)$ & $147(0.96 \%)$ & 0.006927921 & Prostate cancer \\
\hline ko00512 & $7(0.57 \%)$ & $30(0.2 \%)$ & 0.008355145 & Mucin type O-glycan biosynthesis \\
\hline ko04919 & $43(3.5 \%)$ & $374(2.45 \%)$ & 0.01077703 & Thyroid hormone signaling pathway \\
\hline ko05226 & $30(2.44 \%)$ & $247(1.62 \%)$ & 0.01495566 & Gastric cancer \\
\hline ko04330 & $28(2.28 \%)$ & $227(1.49 \%)$ & 0.01511225 & Notch signaling pathway \\
\hline ko04975 & $12(0.98 \%)$ & $76(0.5 \%)$ & 0.01751861 & Fat digestion and absorption \\
\hline ko00562 & $15(1.22 \%)$ & $105(0.69 \%)$ & 0.0203857 & Inositol phosphate metabolism \\
\hline \multicolumn{5}{|l|}{ CT-vs-PIC } \\
\hline ko00562 & $22(1.45 \%)$ & $105(0.69 \%)$ & 0.0005556445 & Inositol phosphate metabolism \\
\hline ko04214 & $30(1.98 \%)$ & $167(1.09 \%)$ & 0.0009830988 & Apoptosis - fly \\
\hline ko04922 & $26(1.71 \%)$ & $138(0.9 \%)$ & 0.001015626 & Glucagon signaling pathway \\
\hline ko04630 & $23(1.52 \%)$ & $124(0.81 \%)$ & 0.002380328 & Jak-STAT signaling pathway \\
\hline ko05223 & $19(1.25 \%)$ & $100(0.65 \%)$ & 0.004151803 & Non-small cell lung cancer \\
\hline ko04070 & $24(1.58 \%)$ & $142(0.93 \%)$ & 0.006645948 & Phosphatidylinositol signaling system \\
\hline ko00564 & $25(1.65 \%)$ & $151(0.99 \%)$ & 0.007416318 & Glycerophospholipid metabolism \\
\hline ko00520 & $15(0.99 \%)$ & $78(0.51 \%)$ & 0.009115605 & Amino sugar and nucleotide sugar metabolism \\
\hline ko05211 & $21(1.38 \%)$ & $124(0.81 \%)$ & 0.01041359 & Renal cell carcinoma \\
\hline ko04120 & $39(2.57 \%)$ & $274(1.79 \%)$ & 0.0137763 & Ubiquitin mediated proteolysis \\
\hline \multicolumn{5}{|l|}{ CT-vs-VH } \\
\hline ko02010 & $24(2.33 \%)$ & $163(1.07 \%)$ & 0.0002372665 & $A B C$ transporters \\
\hline ko04922 & $20(1.94 \%)$ & $138(0.9 \%)$ & 0.0009303992 & Glucagon signaling pathway \\
\hline ko04931 & $22(2.14 \%)$ & $169(1.11 \%)$ & 0.002216142 & Insulin resistance \\
\hline ko04520 & $24(2.33 \%)$ & $197(1.29 \%)$ & 0.00347834 & Adherens junction \\
\hline & $4(0.39 \%)$ & $11(0.07 \%)$ & 0.004603775 & Circadian rhythm - fly \\
\hline
\end{tabular}


Table 4 The top 10 KEGG pathways with the highest enrichment of DEGs in groups with different immune challenges (Continued)

\begin{tabular}{|c|c|c|c|c|}
\hline Pathway ID & $\begin{array}{l}\text { DEGs annotation in the } \\
\text { pathway }\end{array}$ & $\begin{array}{l}\text { All genes annotation in the } \\
\text { pathway }\end{array}$ & $\boldsymbol{P}$-values & Pathway annotation \\
\hline \multicolumn{5}{|l|}{ ko04711 } \\
\hline ko04710 & $7(0.68 \%)$ & $35(0.23 \%)$ & 0.007846637 & Circadian rhythm \\
\hline ko00562 & $14(1.36 \%)$ & $105(0.69 \%)$ & 0.01068485 & Inositol phosphate metabolism \\
\hline ko01523 & $13(1.26 \%)$ & $95(0.62 \%)$ & 0.01105092 & Antifolate resistance \\
\hline ko00534 & $10(0.97 \%)$ & $65(0.43 \%)$ & 0.01116436 & $\begin{array}{l}\text { Glycosaminoglycan biosynthesis-heparan sulfate / } \\
\text { heparin }\end{array}$ \\
\hline ko04962 & 10 (0.97\%) & $65(0.43 \%)$ & 0.01116436 & Vasopressin-regulated water reabsorption \\
\hline
\end{tabular}

members of TSP/TPO family contain repeated type 1 thrombospondin domains. The BCL/CLL family cytokines contain a conserved N-terminal domain that is found in the BCL7 family. The predicted IL-17, IL-17-2, IL-17B, and IL-17C/E in the IL-17 family commonly contain a cysteine knot fold domain.

\section{Transcript expression of cytokines in the coelomocytes with dosage-increased LPS treatment}

The selected cytokines were applied to study their expressing upon LPS treatments of increased concentrations of $10.0 \mu \mathrm{g} / \mathrm{ml}, 20.0 \mu \mathrm{g} / \mathrm{ml}$ and $50.0 \mu \mathrm{g} / \mathrm{ml}$. As the result, the mRNA levels of IL-17 cytokines family were significantly upregulated after $10 \mu \mathrm{g} / \mathrm{ml}$ LPS challenge, and their expression levels generally showed a trend of first increasing, then decreasing, and finally stabilizing with the increasing of LPS concentration (Fig. 6). In the BCL/CLL family, with the increase of LPS concentration, BCL10, CLL7A, CLL9-X3b and CLL9-X3c showed a dose-dependent increasing expression pattern, similar to the expression patterns of TPO-I-7A2 and TPO-I-7A2 in the TSP/TPO family. In contrast, CCL11A, BCL3-X3, CLL9-X3a and CLL9-X3d were expressed in a dosedependent descending pattern, similar to the expression trends of TPO-I-7B1-3 and TSP-4 in the TSP/TPO family. In the EPRF1 family, EDRF1a, EDRF1b, EDRF1c, and EDRF1d showed similar parallel expression patterns, which first increased, then decreased, and finally stabilized with increasing of LPS concentrations (Fig. 6).

\section{Discussion}

Based on Illumina HiSeq2500 sequencing, a transcriptome for the sea cucumber primary coelomocytes under challenges of LPS, Poly (I: C) and $V$. harveyi was obtained in this study. Without referenced genomic data, the assembled Unigene sequences were annotated using the databases of nucleotides and genomes of other species. There are 28.98 and $31.91 \%$ of the unigenes that annotated to the NR database were matched to the sequences from $S$. purpuratus and $A$. planci, respectively. One of the possible reason is that the first two reference genomes databases were supplied in these two species [27, 28]. However, other two studies for the genome of the sea cucumber A. japonicas have been published recently $[19,29]$, which can provide more conveniences for annotating the genes in the transcriptome of other sea cucumber speices in the future.

A Unigene in the transcriptomic data is declared differentially expressed if a difference observed in read counts between the experimental and control conditions is statistically significant. Thirteen Unigenes were selected from the DEGs for RT-qPCR verification (Fig. 2c $\& \mathrm{~d})$. The results showed that the trends of gene expression by RT-qPCR were consistent with those by RNAseq analysis, verifying the credibility of the RNA- seq results.

The co-expressed DEGs in all three groups with different immune challenge [LPS, Poly (I: C) and $V$. harveyi] may speculated to be the essential genes of the immune defense in sea cucumber, while the DEGs unique to a kind of immune stimuli may specifically respond to the corresponding stimuli. LPS is the main component of the wall of gram-negative bacteria, as a typical endotoxin, can bind to the CD14/TLR4/MD2 complexes in many cell types, especially monocytes, dendritic cells, macrophages and B cells, which can promote the secretion of pro-inflammatory cytokines, nitric oxide and eicosenoic acid, leading to a series of immune responses in the host [30]. In the LPS-treatment group, the Th1 and Th2 cell differentiation pathway was the most significantly enriched immune-related pathway. Poly (I:C), structurally similar to double-stranded RNA [31], is an immune activator that is used to mimic viral infection, and it is known to interact with TLR3, which is expressed on the cell membrane of B cells, macrophages and dendritic cells. In the Poly (I:C) treatment group, the intestinal immune network for IgA production pathway was the most significantly enriched immune-related 
Table 5 The top 10 immune-related KEGG pathways with the highest enrichment of DEGs in groups with different immune challenges

\begin{tabular}{|c|c|c|c|c|}
\hline Pathway ID & DEGs annotation in the pathway & All genes annotation in the pathway & $\boldsymbol{P}$-values & Pathway annotation \\
\hline \multicolumn{5}{|l|}{ CT-vs-LPS } \\
\hline ko04658 & $21(1.71 \%)$ & $218(1.43 \%)$ & 0.2218435 & Th1 and Th2 cell differentiation \\
\hline ko04670 & $20(1.63 \%)$ & $208(1.36 \%)$ & 0.2311792 & Leukocyte transendothelial migration \\
\hline ko04650 & $11(0.9 \%)$ & $115(0.75 \%)$ & 0.3179508 & Natural killer cell mediated cytotoxicity \\
\hline ko04666 & $14(1.14 \%)$ & $155(1.01 \%)$ & 0.3636409 & Fc gamma R-mediated phagocytosis \\
\hline ko04659 & $8(0.65 \%)$ & $88(0.58 \%)$ & 0.4117395 & Th17 cell differentiation \\
\hline ko05340 & $4(0.33 \%)$ & $42(0.27 \%)$ & 0.4392712 & Primary immunodeficiency \\
\hline ko04623 & $9(0.73 \%)$ & $105(0.69 \%)$ & 0.4703544 & Cytosolic DNA-sensing pathway \\
\hline ko04640 & $4(0.33 \%)$ & $46(0.3 \%)$ & 0.5109961 & Hematopoietic cell lineage \\
\hline ko04664 & $8(0.65 \%)$ & $98(0.64 \%)$ & 0.5344647 & Fc epsilon RI signaling pathway \\
\hline ko04672 & $2(0.16 \%)$ & $23(0.15 \%)$ & 0.561599 & Intestinal immune network for IgA production \\
\hline \multicolumn{5}{|l|}{ CT-vs-PIC } \\
\hline ko04672 & $6(0.4 \%)$ & $23(0.15 \%)$ & 0.02188151 & Intestinal immune network for IgA production \\
\hline ko04670 & $28(1.84 \%)$ & $208(1.36 \%)$ & 0.05993948 & Leukocyte transendothelial migration \\
\hline ko04650 & $17(1.12 \%)$ & $115(0.75 \%)$ & 0.06204072 & Natural killer cell mediated cytotoxicity \\
\hline ko04666 & $21(1.38 \%)$ & $155(1.01 \%)$ & 0.08842557 & Fc gamma R-mediated phagocytosis \\
\hline ko04664 & $13(0.86 \%)$ & $98(0.64 \%)$ & 0.1727241 & Fc epsilon Rl signaling pathway \\
\hline ko04623 & $13(0.86 \%)$ & $105(0.69 \%)$ & 0.2419115 & Cytosolic DNA-sensing pathway \\
\hline ko04640 & $6(0.4 \%)$ & $46(0.3 \%)$ & 0.3049254 & Hematopoietic cell lineage \\
\hline ko04662 & $12(0.79 \%)$ & $102(0.67 \%)$ & 0.312857 & B cell receptor signaling pathway \\
\hline ko04620 & $13(0.86 \%)$ & $118(0.77 \%)$ & 0.3906605 & Toll-like receptor signaling pathway \\
\hline ko05340 & $5(0.33 \%)$ & $42(0.27 \%)$ & 0.4066475 & Primary immunodeficiency \\
\hline \multicolumn{5}{|l|}{ CT-vs-VH } \\
\hline ko04666 & $17(1.65 \%)$ & $155(1.01 \%)$ & 0.03195124 & Fc gamma R-mediated phagocytosis \\
\hline ko04062 & $18(1.75 \%)$ & $188(1.23 \%)$ & 0.08324536 & Chemokine signaling pathway \\
\hline ko05340 & $5(0.49 \%)$ & $42(0.27 \%)$ & 0.1499922 & Primary immunodeficiency \\
\hline ko04650 & $11(1.07 \%)$ & $115(0.75 \%)$ & 0.1515229 & Natural killer cell mediated cytotoxicity \\
\hline ko04672 & $3(0.29 \%)$ & $23(0.15 \%)$ & 0.1992882 & Intestinal immune network for IgA production \\
\hline ko04664 & $9(0.87 \%)$ & $98(0.64 \%)$ & 0.2139022 & Fc epsilon Rl signaling pathway \\
\hline ko04659 & $8(0.78 \%)$ & $88(0.58 \%)$ & 0.2403939 & Th17 cell differentiation \\
\hline ko05321 & $2(0.19 \%)$ & $14(0.09 \%)$ & 0.2423557 & Inflammatory bowel disease (IBD) \\
\hline ko04662 & $9(0.87 \%)$ & $102(0.67 \%)$ & 0.2484696 & B cell receptor signaling pathway \\
\hline ko04623 & $9(0.87 \%)$ & $105(0.69 \%)$ & 0.2755423 & Cytosolic DNA-sensing pathway \\
\hline
\end{tabular}

pathway. V. harveyi is a gram-negative marine bacterium that is pathogenic to commercial aquaculture species, including shrimp, fish, and sea cucumber [32]. In the $V$. harveyi treatment group, the Fc gamma R-mediated phagocytosis pathway was the most significantly enriched immune-related pathway. Annotation of the DEGs into the immune-related pathways provides a basis for the research of immune molecular mechanism of echinoderms.

For analysis of DEGs in the coelomocytes with different immune challenges, the results showed that compared with the control group, more down-regulated DEGs than up-regulated DEGs were presented in the groups challenged with three different immune stimuli (Fig. 2b), indicating that the expression for a majority of genes were suppressed by immune challenge. The top 10 significantly enriched KEGG pathways (Tables 2 and 4) and immune-related KEGG pathways (Tables 3 and 5) for common and specific immune challenged DEGs were further screened out. Based on the transcriptomic data in this study, the cDNAs of $H$. leucospilota Fasassociated death domain (FADD) have been cloned with 


\section{A Log2 fold changes of cytokines in different challenge}

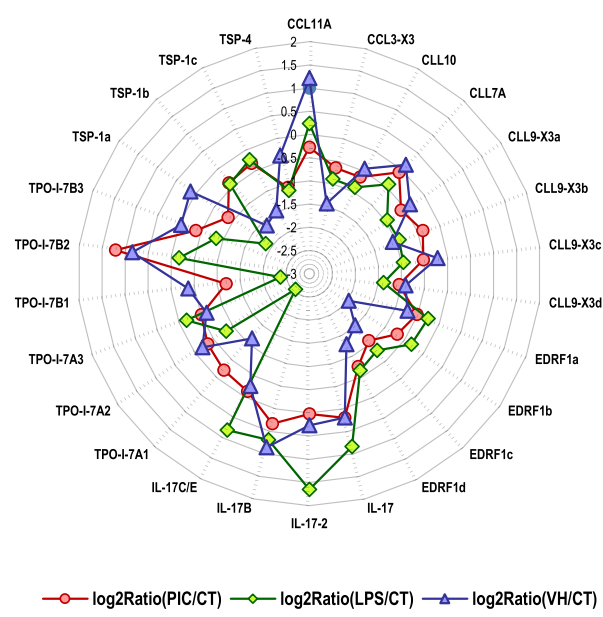

B FPKM of cytokines in different challenge

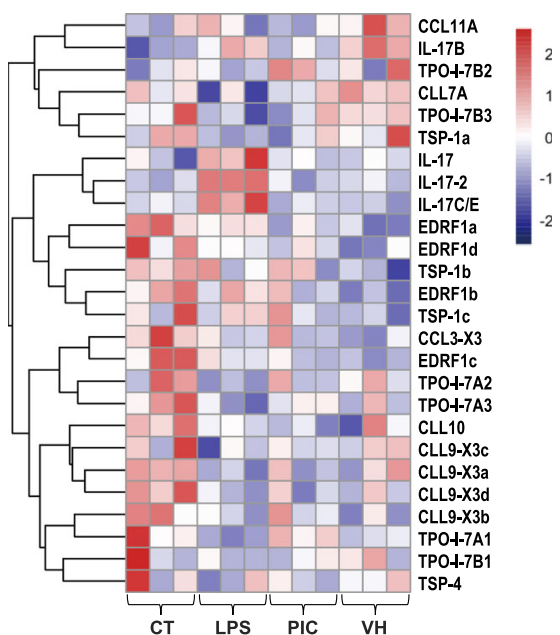

Fig. 4 Changes in expression of cytokine genes upon immune challenges of LPS, Poly (I: C) and V. harveyi. a The periphery of the circle is the Xaxis which presents cytokine genes, while the radius of the circle is the $Y$-axis which presents the $\log 2$ fold changes value of LPS, Poly (I:C) and $V$. harveyi immune challenges of corresponding cytokine genes. The closer from the edge of the circle the higher the up regulated expression of corresponding gene is, and the closer from the center of the circle the higher the down regulated expression of corresponding gene is. $\mathbf{b}$ twodimensional hierarchical clustering performed on the clusters of cytokine genes FPKM under three different stimulis. The pink and blue color represents the up- and down-regulation, respectively

A Phylogenetic analysis of cytokines

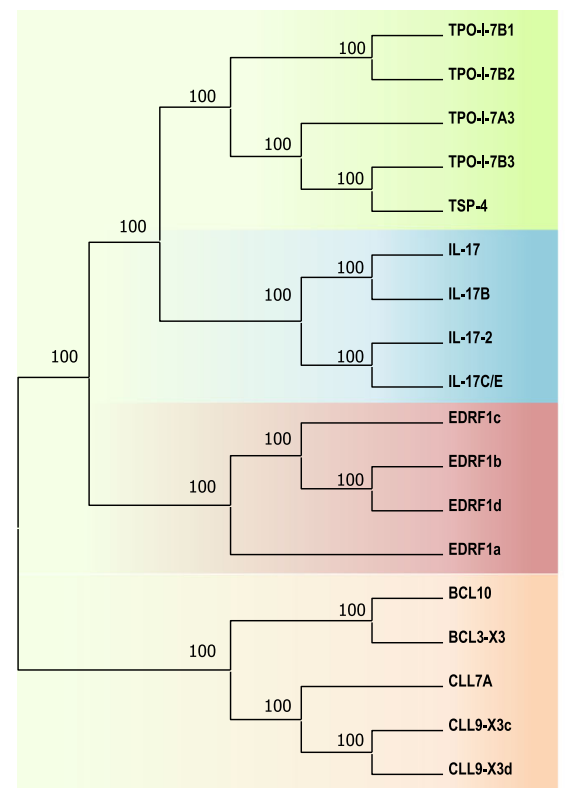

B Structural domains of cytokines
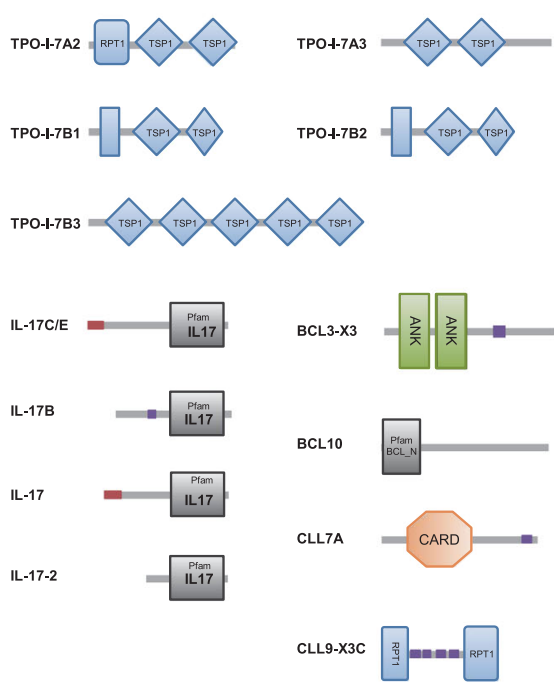

Fig. 5 Bioinformatics analysis of selected cytokines. a Phylogenetic analysis of the selected cytokines family with maximum-likelihood (ML) method. $\mathbf{b}$ The structural domains of some of the cytokines 

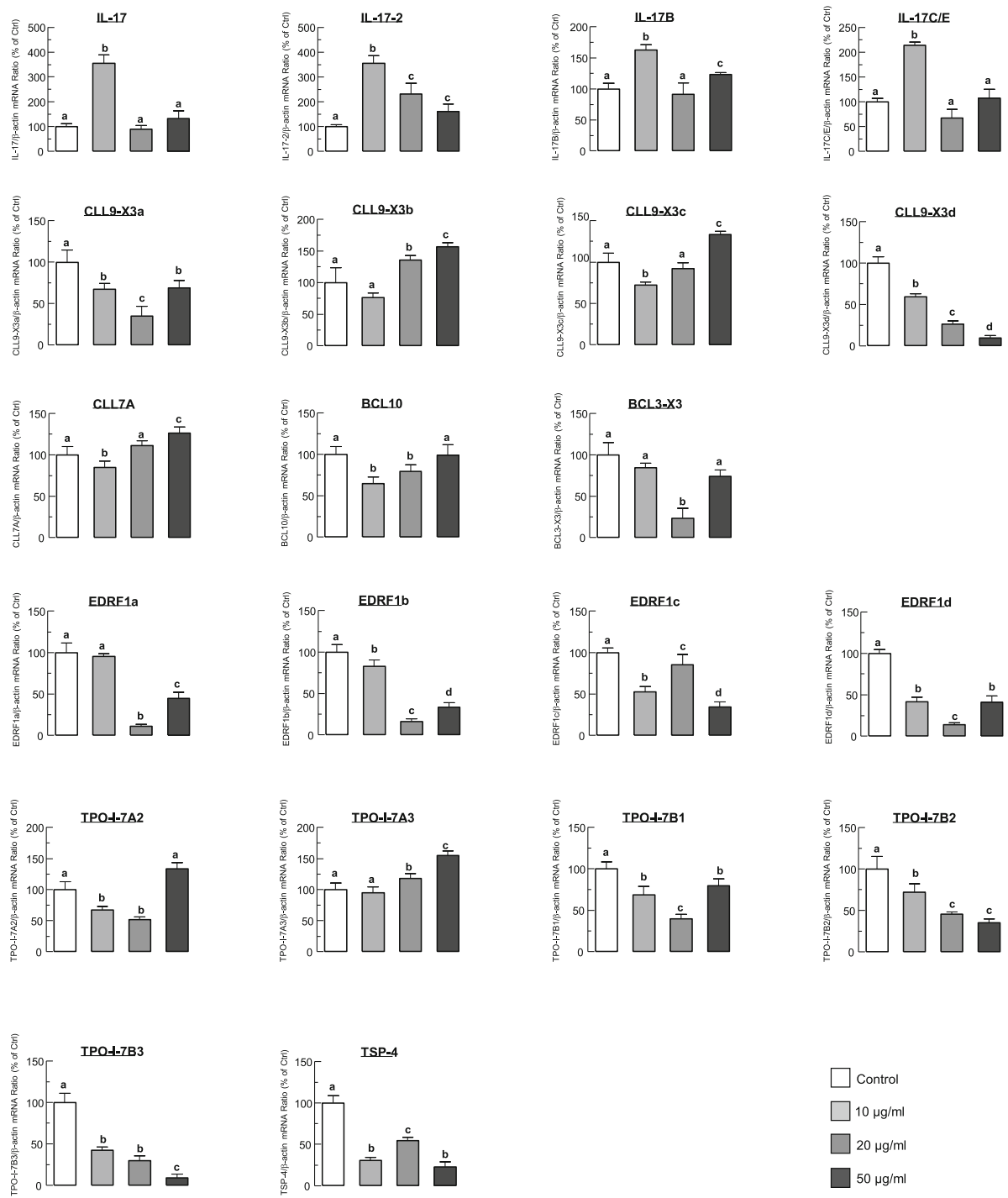

Fig. 6 Dose-increased expression of cytokine genes. Transcriptional expression of H. leucospilota cytokines gene, with the $\beta$-actin as reference gene, in the sea cucumber coelomocytes treated respectively with LPS concentration of $10.0 \mu \mathrm{g} / \mathrm{ml}, 20.0 \mu \mathrm{g} / \mathrm{ml}, 50.0 \mu \mathrm{g} / \mathrm{ml}$ for $24 \mathrm{~h}$. The data presented are expressed as the mean \pm S.E. $(n=3)$. The same letter in the experimental groups represent a similar level $(p>0.05$, ANOVA followed by Fisher's LSD test)

functional characterization [33] It has been reported that there are many humoral immune factors in the coelomic fluid of echinoderms that can recognize and attack the invaded pathogens, including different types of lectin, lysozyme, hemolysin, hydrolase, phenol oxidase, superoxide dismutase, nitric oxide synthase and complementlike factor [6, 9, 34-36]. Similarly, a number of humoral immune factors in the corresponding immune-related pathways (Table 5) were identified in the current study.

The top 10 KEGG pathways for the most significant DEG enrichment after different immune challenges also included amino acid and carbohydrate metabolic pathways, such as alanine, aspartate and glutamate metabolism pathway, amino sugar and nucleotide sugar metabolism pathway, and glycosaminoglycan biosynthesis-heparan sulfate/heparin pathway (Table 4). A similar study performed in in the sea cucumber A. japonicas has reported that the arginine metabolic pathway is related to the pathogenic challenge with a dose-dependent manner [37]. Combined with our current study, it is speculated that the metabolism of some amino acids is related to the host immune response in echinoderm, and the regulatory network between immunity and metabolism is more complicated than known now.

Based on the DEGs identified in the transcriptome of sea cucumber coelomocytes challenged with immune stimuli, twenty-one candidate genes of immune cytokines were selected for analyzing the cytokine response 
of sea cucumber against invaded pathogens. The selected cytokines belong to four cytokine families, namely, the TSP/TPO, BCL/CLL, EPRF1 and IL-17 families (Fig. 5a). Among these gene families, the expression levels of 4 genes in the IL-17 family after LPS challenge were significantly higher than those of other cytokines. By further confirmation with RT- $\mathrm{qPCR}$ of the expression levels of 4 IL-17 s generally showed a trend of first increasing, then decreasing, and finally stabilizing with incubation of LPS with increasing concentrations (Fig. 6). IL-17 is a kind of potent proinflammatory cytokine produced by activated memory $\mathrm{T}$ cells in mammals [38]. The IL-17 family (of which there are 6 known members, termed IL-17A to IL-17F) is thought to represent a distinct signaling system that appears to highly conserved across vertebrate evolution [38]. IL-17 family members play an active role in inflammatory diseases, autoimmune diseases and cancer [39]. Based on the identification of differentially expressed cytokine genes in the sea cucumber coelomocytes under immune challenges, this study may provide an evidence that many kinds of cytokines interact with each other, and play a complex and essential role in the innate immunity of sea cucumber.

At present, more and more studies on the immune system of the sea cucumber have been developed at both the molecular and cellular levels, which were based on the basal information for immune-related genes that provided by the transcriptomic studies [25]. However, the specific immune defense mechanism in the effector coelomocytes is still unclear. In this study, highthroughput transcriptome sequencing and bioinformatics analysis were performed on coelomocytes treated with three different immune stimuli (LPS, Poly (I:C) and Vibrio harveyi). Analysis of the results could elucidate the molecular mechanism for the immune response in the sea cucumber coelomocytes to the pathogenic/immune challenge, laying a foundation for the future identification of immune-related genes and characterizations of immune-responded mechanisms of echinoderm.

\section{Conclusions}

In this study, comparative transcriptome analysis of DEGs among LPS $(10 \mu \mathrm{g} / \mathrm{ml})$, Poly (I:C) $(10 \mu \mathrm{g} / \mathrm{ml})$ and heat-inactivated Vibrio harveyi $\left(10^{7}\right.$ cells $\left./ \mathrm{ml}\right)$ immune stimuli of sea cucumber $\mathrm{H}$. leucospilota coelomocytes revealed the DEGs and immune-related pathways that are crucial for research of molecular mechanisms related to the immune response in echinoderms. Twenty-one cytokine candidate DEGs were identified, which belong to 4 cytokine families, namely, BCL/CLL, EPRF1, IL-17 and TSP/TPO. Among them IL-17 family cytokines were significantly upregulated after $10 \mu \mathrm{g} / \mathrm{ml}$ LPS challenge for $24 \mathrm{~h}$ in response to LPS dose-increased treatment (0, 10,20 and $50 \mu \mathrm{g} / \mathrm{ml}$ ), which provide new insights for the echinoderm cytokine response during immune challenge.

\section{Methods \\ Animals}

Animals used in this research were obtained from commercial sea cucumber catches, therefore approval from any ethics committee or institutional review board was not necessary. A total of nine healthy $H$. leucospilota weighing 190-210 g were obtained from the Daya Bay in Guangdong province, China, and maintained in a seawater aquarium with aerated and filtrated seawater (30\% salinity) at $32{ }^{\circ} \mathrm{C}$ for 1 week before the experiments were performed.

\section{Isolation, primary culture and static incubation of coelomocytes}

Given that coelomocytes are considered as the immune effector cells in echinoderms [10], the coelomocytes from $H$. leucospilota were applied to explore the response of sea cucumber after challenge of immune stimuli. Isolation of primary cells and static incubation of coelomocytes were performed as previously reported with some modifications [40, 41]. Briefly, three sea cucumbers were washed with sterile DEPC water three times before dissection on ice. The coelomic fluids were sieved through a 150-mesh cell sieve to remove large tissue debris, mixed with the prechilled anticoagulant solution $(20 \mathrm{mM}$ EGTA, $480 \mathrm{mM} \mathrm{NaCl}, 19 \mathrm{mM} \mathrm{KCl}$ and 68 $\mathrm{mM}$ Tris, $\mathrm{pH}$ 7.6) in a 1:1 volume ratio. The cell suspension was filtered through a $100-\mu \mathrm{m}$ nylon mesh, and the cells were collected by centrifugation at $500 \times \mathrm{g}$ at $4{ }^{\circ} \mathrm{C}$ for $10 \mathrm{~min}$. The harvested cells were washed twice with $30 \mathrm{ml}$ isotonic buffer (1 mM EGTA, $530 \mathrm{mM} \mathrm{NaCl}$ and $10 \mathrm{mM}$ Tris, $\mathrm{pH}$ 7.6) and resuspended in $10 \mathrm{ml}$ Leiboviz's L-15 cell culture medium (Gibco BRL, USA; containing $390 \mathrm{mM} \mathrm{NaCl}, 100 \mathrm{U} / \mathrm{mL}$ penicillin and $100 \mu \mathrm{g} / \mathrm{ml}$ streptomycin, $\mathrm{pH} 7.6)$ and filtered through a $40-\mu \mathrm{m}$ nylon mesh to remove the cell clusters. The cell yield was counted with a $0.10-\mathrm{mm}$ hematocytometer, and only the cell preparations with greater than 95\% viability, assessed by trypan blue exclusion assay, were used in subsequent experiments.

The cell suspensions were diluted to $0.1 \times 10^{6} \mathrm{cells} / \mathrm{ml}$ and seeded onto two 24-well culture plates $(1 \mathrm{ml} /$ well $)$ that were precoated with ploy D-lysine. The isolated coelomocytes were incubated at $28^{\circ} \mathrm{C}$ for another $18 \mathrm{~h}$ for recovery. On the following day, $1 \mathrm{ml}$ of immune stimulus prepared in Leiboviz's L-15 medium was gently overlaid onto the cells after removal of the old medium. The immune stimuli used in this study included: LPS $(10 \mu \mathrm{g} / \mathrm{ml})$, Poly (I:C) $(10 \mu \mathrm{g} / \mathrm{ml})$ and heat-inactivated Vibrio harveyi $\left(10^{7}\right.$ cells $\left./ \mathrm{ml}\right)$, and fresh Leiboviz's L-15 medium was used as a control. For RNA sequencing, the 
cells were harvested at $24 \mathrm{~h}$ after incubation of tested substrates. In this case, cells from four wells were pooled together as a biological duplicate, and three duplicates for each group were sequenced and analyzed.

\section{RNA extraction, library construction and sequencing}

Total RNA from each sample was extracted using TRIzol Reagent (Invitrogen, USA). The quality and concentration of total RNA were determined with NanoDrop (Thermo Scientific, USA), and the RNA integrity value (RIN) was checked using the RNA 6000 Pico LabChip on an Agilent 2100 Bianalyzer (Agilent, USA). The RNA-seq library was constructed in six steps: 1) ployAtailed mRNAs were enriched by oligo (dT) selection; 2) the obtained mRNAs were fragmented and reverse transcribed into double-stranded cDNA (dscDNA) by $\mathrm{N} 6$ random primer; 3 ) the cDNA ends were repaired by 3 'adenylation and adaptor ligation; 4) the ligation products were amplified by PCR; 5) the PCR products were heatdenatured and the single-stranded DNAs were cyclized; and 6) sequencings were performed on an Illumina HiSeq2500 (Illumina, USA).

\section{De novo assembly and Unigene functional annotation}

The raw sequencing data were first filtered by using SOAPnuke (v1.5.2) software under the parameters of -1 15 -q $0.2-n 0.1$ to remove the reads in which unknown bases $(\mathrm{N})$ are more than $5 \%$. The low quality reads, which were defined by the base qualities for more than $20 \%$ of them were less than 15 , were then removed. After reads filtering, de novo assembly was performed using Trinity2.0.6 with clean reads [42]. Tgicl2.0.6 was used on cluster transcripts to remove redundancy and get Unigenes [43]. After assembly, the Unigenes functional annotation were performed with seven functional databases, namely NR, NT, GO, KOG, KEGG, SwissProt and InterPro. Specifically, We use Blastn 2.2.23 [44], We use Blastx 2.2.23 [44] or Diamond 0.8.31 [45] align Unigenes to NT, NR, KOG, KEGG and SwissProt database to do the annotation, use Blast2GO 2.5.0 [46] with NR annotation to do the GO annotation, and use InterProScan5 5.11-51.0 [47] to do the InterPro annotation, under default parameter.

\section{Quantification of gene expression level and identification of DEGs}

Clean reads of each sample were mapped to the Unigenes with Bowtie2 2.2.5 [48], and the gene expression levels were calculated with RSEM 1.2.12 (RNA-Seq by Expectation-Maximization) to obtain the FPKM (Fragments Per Kilobase of exon model per Million mapped reads) value [49]. The DEGseq algorithm was used to detect the differences of gene expression between different groups. To improve the accuracy of DEGs, genes with over two-fold changes $(\log 2$ ratio $\geq 1)$ and q-value $<0.001$ were considered as significantly DEGs.

\section{Screening and analysis of immune-related pathways}

Based on Wallenius non-central hyper-geometric distribution [50], GO enrichment analysis of the differentially expressed genes (DEGs) was implemented by the GOseqR packages 1.10.0, which can be adjusted for gene length bias in DEGs. KOBAS (KEGG Orthology-Based AnnotationSystem) software was used to test the statistical enrichment of DEGs in KEGG pathways. The FDR correction was performed for $p$-value, and pathways with FDR $<0.01$ were regarded as significantly enriched pathways. The top 10 immune-related pathways significantly enriched in the groups treated with different stimuli were selected by the immune-related annotation of the KEGG pathways.

\section{Validation of differentially expressed genes by RT-qPCR} Significant DEGs $(P<0.05$, FDR $<0.05$, fold change $\geq 8)$ were selected for RT-qPCR analysis to validate the transcriptomic data, and corresponding primers were designed by based on the Unigenes sequences (Table 1). The primary coelomocytes isolated from another three $H$. leucospilotas were then challenge by LPS $(10 \mu \mathrm{g} / \mathrm{ml})$ for $24 \mathrm{~h}$. Total RNA from each sample was extracted using TRIzol Reagent and reverse transcribed into the first cDNA using Honorll 1st strand cDNA Synthesis SuperMix for qPCR kit (Novogene, China). Finally, quantitative real-time PCRs were performed using the Unique Aptamer qPCR SYBR probe kit (Novogene). In this case, the qPCRs were performed in triplicates for cells cultured in three individual wells.

\section{Identification and bioinformatics analysis of cytokines responding to immune challenge}

According to the NR annotation of the transcriptomic data from the coelomocytes challenged by LPS, Poly (I:C) and $V$. harveyi, Twenty-one candidate cytokine genes were selected. The log2-fold changes of their expression levels under different challenges were presented as heatmap by the Pheatmap package using R3.5 software [51, 52].

The CDSs of the candidate cytokine genes were translated to amino acid sequences to construct a maximumlikelihood phylogenetic tree with 1000 bootstrap replicates by using MEGA 7. The structural domains of the cytokines were predicted by using the SMART program.

\section{Measurement of cytokines mRNA levels in coelomocytes after LPS challenge}

Primers for the selected cytokine genes were designed by based on their Unigenes sequences (Table 6). The primary coelomocytes isolated from the other three $\mathrm{H}$. leucospilotas were obtained after treatment of LPS in 
Table 6 Primers designed for RT-qPCR of DEGs

\begin{tabular}{|c|c|c|c|}
\hline Gene ID & $\boldsymbol{P}$-values & Forward primer sequences $\left(5^{\prime}-3^{\prime}\right)$ & Reverse primer sequences $\left(5^{\prime}-3^{\prime}\right)$ \\
\hline \multicolumn{4}{|c|}{ Differentially expressed genes(DEGs) } \\
\hline CL3876.Contig4_Mix & 0 & TCACGGCATTGAGAACGG & CGGTGTCTGAACTTTGGGT \\
\hline Unigene38924_Mix & 0 & CAGACAAAAGCCTCAGAAATG & AAGAACCCAGAGCTGGAAAG \\
\hline Unigene36248_Mix & 0 & ATACGAAAAGCGGCAAACA & TCCATCTCAGACCCCAACTC \\
\hline Unigene1474_Mix & 0 & TCCATCTCAGACCCCAACTC & TTTCCATTGGGAGGTAAGC \\
\hline Unigene6464_Mix & 0 & TCACTGCGGCATTGATTC & GGTGCCCTTCCGTCAATT \\
\hline Unigene36250_Mix & 0 & GTGCAAAGAAGGGAAGGC & TCTGGTGATTATGTTGTGGG \\
\hline Unigene42438_Mix & 0 & ACTCATGTGGATGGCACTAGC & GGAAGAAGGGACAGAATAAACC \\
\hline CL3998.Contig1_Mix & 1.89E-260 & AAGGATTATGGACGGGACAC & TTCTCAAACCACCAGAGGG \\
\hline Unigene1910_Mix & 0 & GTCAAACCAATAACAGCGAAAG & TGGACCAGACCAGGCAAA \\
\hline Unigene27584_Mix & 0 & CGTGCTTGCCGAGTTTGT & GCAGGCTATTGCTGTTGTTAA \\
\hline CL657.Contig6_Mix & 0 & AAGCAAGATAGACACTGTGGTTC & GATTGATGCCCCGTAAGC \\
\hline CL3619.Contig1_Mix & 0 & AGGGTAACAGGTTGGGTGAA & GCAGTAGTTGGAGCCATTGAA \\
\hline Unigene11374_Mix & 0 & TGCGTTTGTTGACTITTGC & TGAAATGGTTCCGATTCTCA \\
\hline Unigene2830_Mix & 0 & TITGCTGGAGTATTGTGGTTC & TGGGCTGTAGGGGCTTTA \\
\hline Unigene6841_Mix & $2.03 E-139$ & ACCCCAGATGACCTTTGACC & GTTAACACAATTTCTCCAGTTAGGA \\
\hline Unigene2638_Mix & 1.05E-297 & AGTTGATATTCACCAGCCTTGC & CCACTITCCATGAAACCGTAA \\
\hline Unigene1366_Mix & $2.56 \mathrm{E}-93$ & GGAGGTCAATGGTCATTTGG & ACCCCTGGTGACCCTACAT \\
\hline Unigene1518_Mix & $7.31 E-233$ & AAACACGGTATCTCCAGAATGA & AATGACCTTTGACCTCCACC \\
\hline Unigene16828_Mix & 0 & TTCAAAAGCAGTGCCAACG & CATTATCATCATCTTGCCGAAC \\
\hline Unigene3853_Mix & $2.50 \mathrm{E}-62$ & CCACTTGGACAGCAGTGAAG & TGATGACCTGGTTTGAGAAGAC \\
\hline \multicolumn{4}{|l|}{ Cytokine genes } \\
\hline CCL3-X3 & 0.000883536 & CGCAAAGGATTGTGATGGT & ACAGGAAGAGGCTATACAGACG \\
\hline CLL10 & 0.013152297 & CTTACTGGGTTGGTAGTITTGAC & GTGCGTTCTTGCCATTCTC \\
\hline CLL7A & 0.00023473 & TCTTGCTTCTCACCCGATTT & CCGTAGGGGACACCTCTTT \\
\hline CLL9-X3a & 5.57E-09 & TGGTGGAATAGTGGAGGGTG & GACTGGTTGGTTGAGGCTGT \\
\hline CLL9-X3b & 0.003436624 & AACAGACGGACAGTCATACAGC & TGGTTGAGCCCTTGATAGTG \\
\hline CLL9-X3C & 0.005767319 & CATTCCAGTTGGTGATGGC & TGATTTCCTCACCGCATTT \\
\hline CLL9-X3d & $2.23 \mathrm{E}-07$ & CAGAAAGCCTGGGTAAAGC & GACCTGGACCAAACCTCATT \\
\hline EDRF1a & 0.101229003 & TTACAAGACTATCCTCCCCTCA & GCGATGCGATACTGATAAAGG \\
\hline EDRF1b & 0.311031428 & ATGGCTITTGAGGATGGTG & GCTGCTGTATCTCAGGAGGAAA \\
\hline EDRF1c & 0.000470648 & ACCAACCACCATCCAACTG & TTCTCCTGATCCACCCCTAA \\
\hline EDRF1d & 0.001415506 & TCCCTTTATTGTTCCTGTGG & TGTCTCCGCTTTCCTGTAGTA \\
\hline IL-17 & $1.94 \mathrm{E}-07$ & AGGCTGGCTCGCTTCTT & ACGCTATCGCTCATTGGAC \\
\hline IL-17-2 & $5.40 \mathrm{E}-08$ & GTTGAGGCATTCACATTTCG & AACTTTCGGCAGTCCTTACAG \\
\hline IL-17B & $1.36 \mathrm{E}-05$ & TACCATAGGAAGGGGATCTGT & AGACTTGCCCGACGATTT \\
\hline IL-17C/E & $3.56 \mathrm{E}-23$ & AGGCACTCTTCTGCATTCTCC & GCTACTGAACGCTTGTTGACG \\
\hline TPO-I-7A2 & 1.90E-07 & CGGCGGCATACAACAGA & ACATTGGGCATCCAGAACA \\
\hline TPO-I-7A3 & 0.003209029 & GGTCCAAAGAAAGGCATCA & GGCTTGAAAGTAAGAAACCGT \\
\hline TPO-I-7B1 & 5.20E-08 & GATTCAGCCTTCATTITGGA & GCTTAGTATCTTTGGGTCTGTCTA \\
\hline TPO-I-7B2 & 0.000343861 & GATTCAGCCTTCATTITGGA & GCTTAGTATCTTTGGGTCTGTCTA \\
\hline TPO-I-7B3 & 0.7252968 & TGGTCCAAGTGGTCTCCCT & CTGGTCCTCTGGTAAACAGTCAT \\
\hline TSP-4 & 0.086692271 & CAGGAGTCTTATTTGGTATCTATGC & CAATGTGGCGATGGTGTTC \\
\hline
\end{tabular}


gradient increased concentrations $(0,10,20$ and $50 \mu \mathrm{g} / \mathrm{ml}$ ) for $24 \mathrm{~h}$. Total RNA extraction, first-strand cDNA synthesis and RT-qPCR were performed as described above. In this case, $\beta$-actin was used as a reference gene, and the RT-qPCRs were performed in triplicates for cells cultured in three individual wells.

\section{Abbreviations}

ANOVA: Analysis of variance; BCL/CLL: B-cell lymphokine; CT: Control group; DEG: Differentially expressed genes; EPRF1: Erythroid differentiation-related factor 1; FPKM: Fragments per kilobase of exon model per million mapped reads; GO: Gene ontology; GSEA: Gene set enrichment analysis; IL17: Interleukin 17; KEGG: Kyoto encyclopedia of genes and genomes; KOG: Clusters of orthologous groups for eukaryotic complete genomes; LPS: Lipopolysaccharide; MAPK: Mitogen-activated protein kinase;

ML: Maximum-likelihood; NGS: Next-generation sequencing;

NR: Nonredundant; PIC: Polyinosinic:polycytidylic acid; Poly (I:C): Polyinosinicpolycytidylic acid; RIN: RNA integrity value; RSEM: RNA-seq by expectationmaximization; RT-qPCR: Real time quantitative polymerase chain reaction; TSP/TPO: Thrombospondin; VH: Vibrio harveyi

\section{Acknowledgements}

We are thankful to Mr. Zezhong, Zhang (Sino-Danish College, University of Chinese Academy of Sciences) and Dr. Hongmei, Li (Institution of South China Sea Ecology and Environmental Engineering, Chinese Academy of Sciences) for help with submitting data.

\section{Authors' contributions}

$\mathrm{T} C$ designed and conducted the experiments, and revised the primer manuscript. XW analyzed the data, wrote the manuscript and carried out the main experiments. D H, Y R, C C, X J and Z Y also participated in carry out a part of the experiments and data analysis. C R supervised, conceived the experiments and corrected the manuscript. All authors read and approved the final manuscript.

\section{Funding}

This study was supported by the National Key R \& D Program of China (2018YFD0901605), the Strategic Priority Research Program of the Chinese Academy of Sciences (XDA13020205), the Science \& Technology Promoting Projects for Oceanic \& Fishery in Guangdong Province (SDYY-2018-01) and the Guangdong Province Program (2017B030314052, 2018A030313857, 2015A030310120, A2015230). The National Natural Science Foundation of China (41676162), the Science and Technology Service Network Initiative of Chinese Academy of Sciences (KFJ-STS-ZDTP-055). The Science and Technology Research Programs of Guangdong Province (2018A030313857). The funding bodies had no role in the design of the study, the collection, analysis, and interpretation of data, and in writing the manuscript and the decision to submit the work for publication.

\section{Availability of data and materials}

RNA-seq data from this article have been deposited in NCBI under the accession number of STUDY: PRJNA559679, SAMPLE: D2CT (SAMN12551561), EXPERIMENT: C1_1 (SRX6693868), RUN: D2CT1_1.fq.gz (SRR9945372), SAMPLE: D2LPS (SAMN12551562), EXPERIMENT: L2_2 (SRX6693869), RUN: D2LPS1_1.fq.gz (SRR9945371), SAMPLE: D2PIC (SAMN12551563), EXPERIMENT: P3_3 (SRX6693870), RUN: D2PIC1_1.fq.gz (SRR9945370), SAMPLE: D2VH (SAMN12551564), EXPERIMENT: V4_4 (SRX6693871), RUN: D2VH1_1.fq.gz (SRR9945369).

\section{Ethics approval and consent to participate}

Animals used in this research were obtained from commercial sea cucumber catches, therefore approval from any ethics committee or institutional review board was not necessary. No ethics approval was required for the collection or experimentation of the animal used in this study, the Holothuria leucospilota.

\section{Consent for publication}

Not applicable.

\section{Competing interests}

The authors declare that they have no competing interests.

\section{Author details}

${ }^{1}$ CAS Key Laboratory of Tropical Marine Bio-resources and Ecology (LMB), Guangdong Provincial Key Laboratory of Applied Marine Biology (LAMB), South China Sea Institute of Oceanology, Chinese Academy of Sciences, Guangzhou 510301, PR China. 'University of Chinese Academy of Sciences, Beijing 100049, PR China. ${ }^{3}$ Institution of South China Sea Ecology and Environmental Engineering, Chinese Academy of Sciences, ISEE, CAS, Guangzhou, PR China. ${ }^{4}$ South China Sea Bio-Resource Exploitation and Utilization Collaborative Innovation Center, Guangzhou 510301, People's Republic of China.

Received: 26 August 2019 Accepted: 24 March 2020

Published online: 16 April 2020

\section{References}

1. Bonham K, Held EE. Ecological observations on the sea cucumbers holothuria atra and $\mathrm{H}$. leucospilota at Rongelap Atoll, Marshall Islands. University of Hawaii Press; 1963. p. 305-14.

2. Huang W, Huo D, Yu ZH, Ren CH, Jiang X, Luo P, Chen T, Hu CQ. Spawning, larval development and juvenile growth of the tropical sea cucumber Holothuria leucospilota. Aquaculture. 2018;488:22-9.

3. Blair JE, Hedges SB. Molecular phylogeny and divergence times of deuterostome animals. Mol Biol Evol. 2005;22(11):2275-84.

4. Qian J, Ren CH, Chen T, Xia JJ, Yu ZH, Gao Y, Hu CQ. Identification and functional characterization of first alpha-2-macroglobulin in sea cucumbers. Aquac Res. 2017;48(5):2278-90.

5. Qian J, Ren CH, Xia JJ, Chen T, Yu ZH, Hu CQ. Discovery, structural characterization and functional analysis of alpha-2-macroglobulin, a novel immune-related molecule from Holothuria atra. Gene. 2016;585(2):205-15.

6. Chen T, Ren $\mathrm{CH}$, Li WH, Jiang X, Xia JJ, Wong NK, Hu CQ. Calmodulin of the tropical sea cucumber: gene structure, inducible expression and contribution to nitric oxide production and pathogen clearance during immune response. Fish Shellfish Immunol. 2015;45(2):231-8.

7. Yan AF, Ren CH, Chen T, Jiang X, Sun HY, Huo D, Hu CQ, Wen J. The first tropical sea cucumber caspase-8 from Holothuria leucospilota: molecular characterization, involvement of apoptosis and inducible expression by immune challenge. Fish Shellfish Immunol. 2018;72:124-31.

8. Yan AF, Ren CH, Chen T, Huo D, Jiang X, Sun HY, Hu CQ. A novel caspase-6 from sea cucumber Holothuria leucospilota: molecular characterization, expression analysis and apoptosis detection. Fish Shellfish Immunol. 2018; 80:232-40.

9. Xue Z, Li H, Wang XL, Li X, Liu Y, Sun J, Liu CJ. A review of the immune molecules in the sea cucumber. Fish Shellfish Immunol. 2015;44(1):1-11.

10. Ramirez-Gomez F, Aponte-Rivera F, Mendez-Castaner L, Garcia-Arraras JE. Changes in holothurian coelomocyte populations following immune stimulation with different molecular patterns. Fish Shellfish Immunol. 2010; 29(2):175-85.

11. Schillaci D, Cusimano MG, Cunsolo V, Saletti R, Russo D, Vazzana M, Vitale M, Arizza V. Immune mediators of sea-cucumber Holothuria tubulosa (Echinodermata) as source of novel antimicrobial and anti-staphylococcal biofilm agents. AMB Express. 2013;3:35.

12. Wang $T$, Sun $Y X$, Jin $L J, X u$ YP, Wang $L$, Ren TJ, Wang KL. Enhancement of non-specific immune response in sea cucumber (Apostichopus japonicus) by Astragalus membranaceus and its polysaccharides. Fish Shellfish Immunol. 2009;27(6):757-62.

13. Mehdi Jazayeri S, Melgarejo Munoz LM, Mauricio Romero H. RNA-SEQ: a glance at technologies and methodologies. Acta Biolo Colomb. 2015;20(2): 23-35.

14. Wang Z, Gerstein M, Snyder M. RNA-Seq: a revolutionary tool for transcriptomics. Nat Rev Genet. 2009;10(1):57-63.

15. Wygoda JA, Yang Y, Byrne M, Wray GA. Transcriptomic analysis of the highly derived radial body plan of a sea urchin. Genome Biol Evol. 2014;6(4):96473.

16. Israel JW, Martik ML, Byrne M, Raff EC, Raff RA, McClay DR, Wray GA. Comparative developmental transcriptomics reveals rewiring of a highly conserved gene regulatory network during a major life history switch in the sea urchin Genus Heliocidaris. PLoS Biol. 2016;14(3):e1002391. 
17. Fuess LE, Eisenlord ME, Closek CJ, Tracy AM, Mauntz R, Gignoux-Wolfsohn S, Moritsch MM, Yoshioka R, Burge CA, Harvell CD, et al. Up in arms: immune and nervous system response to sea star wasting disease. PLoS One. 2015; 10(7):e0133053.

18. Janies DA, Witter Z, Linchangco GV, Foltz DW, Miller AK, Kerr AM, Jay J, Reid RW, Wray GA. EchinoDB, an application for comparative transcriptomics of deeply-sampled clades of echinoderms. BMC Bioinformatics. 2016;17(1):48.

19. Zhang XJ, Sun LN, Yuan JB, Sun YM, Gao Y, Zhang LB, Li SH, Dai H, Hamel $J F$, Liu CZ, et al. The sea cucumber genome provides insights into morphological evolution and visceral regeneration. PLoS Biol. 2017;15(10): 31.

20. Mashanov VS, Zueva OR, Garcia-Arraras JE. Transcriptomic changes during regeneration of the central nervous system in an echinoderm. BMC Genomics. 2014;15:357

21. Mu C, Wang R, Li T, Li Y, Tian M, Jiao W, Huang X, Zhang L, Hu X, Wang S, et al. Long non-coding RNAs (IncRNAs) of sea cucumber: large-scale prediction, expression profiling, non-coding network construction, and IncRNA-microRNA-gene interaction analysis of IncRNAs in Apostichopus japonicus and Holothuria glaberrima during LPS challenge and radial organ complex regeneration. Mar Biotechnol. 2016;18(4):485-99.

22. Zhao $Y$, Yang H, Storey KB, Chen M. RNA-seq dependent transcriptional analysis unveils gene expression profile in the intestine of sea cucumber Apostichopus japonicus during aestivation. Comp Biochem Physiol Part D Genomics Proteomics. 2014;10:30-43.

23. Li Y, Kikuchi M, Li X, Gao Q, Xiong Z, Ren Y, Zhao R, Mao B, Kondo M, Irie N, et al. Weighted gene co-expression network analysis reveals potential genes involved in early metamorphosis process in sea cucumber Apostichopus japonicus. Biochem Biophys Res Commun. 2018;495(1):1395-402.

24. Xing L, Sun L, Liu S, Li X, Zhang L, Yang H. De novo assembly and comparative transcriptome analyses of purple and green morphs of Apostichopus japonicus during body wall pigmentation process. Comp Biochem Physiol Part D Genomics Proteomics. 2018;28:151-61.

25. Gao QLM, Wang Y, et al. Transcriptome analysis and discovery of genes involved in immune pathways from coelomocytes of sea cucumber (Apostichopus japonicus) after Vibrio splendidus challenge. Int J Mol Sci. 2015;16(7):16347-77.

26. Subramanian A, Tamayo P, Mootha VK, Mukherjee S, Ebert BL, Gillette MA, Paulovich A, Pomeroy SL, Golub TR, Lander ES, et al. Gene set enrichment analysis: a knowledge-based approach for interpreting genome-wide expression profiles. Proc Natl Acad Sci U S A. 2005;102(43):15545-50.

27. Sea Urchin Genome Sequencing C, Sodergren E, Weinstock GM, Davidson EH, Cameron RA, Gibbs RA, Angerer RC, Angerer LM, Arnone MI, Burgess DR, et al. The genome of the sea urchin Strongylocentrotus purpuratus. Science. 2006;314(5801):941-52.

28. Hall MR, Kocot KM, Baughman KW, Fernandez-Valverde SL, Gauthier MEA, Hatleberg WL, Krishnan A, McDougall C, Motti CA, Shoguchi E, et al. The crown-of-thorns starfish genome as a guide for biocontrol of this coral reef pest. Nature. 2017;544(7649):231-+.

29. Li YL, Wang RJ, Xun XG, Wang J, Bao LS, Thimmappa R, Ding J, Jiang JW, Zhang LH, Li TQ, et al. Sea cucumber genome provides insights into saponin biosynthesis and aestivation regulation. Cell Discov. 2018;4:29.

30. Glinski Z, Jarosz J. Immune phenomena in echinoderms. Arch Immunol Ther Exp. 2000;48(3):189-93.

31. Fortier ME, Kent S, Ashdown H, Poole S, Boksa P, Luheshi GN. The viral mimic, polyinosinic : polycytidylic acid, induces fever in rats via an interleukin-1-dependent mechanism. Am J Phys Regul Integr Comp Phys. 2004:287(4):R759-66

32. Li Y, Xu X-L, Zhao D, Pan L-N, Huang C-W, Guo L-J, Lu Q, Wang J. TLR3 ligand poly IC attenuates reactive Astrogliosis and improves recovery of rats after focal cerebral ischemia. CNS Neurosci Ther. 2015;21(11):905-13.

33. Zhao L, Ren C, Chen T, Sun H, Wu X, Jiang X, Huang W. The first cloned sea cucumber FADD from Holothuria leucospilota: molecular characterization, inducible expression and involvement of apoptosis. Fish Shellfish Immunol. 2019;89:548-54

34. Shao Y, Che Z, Xing R, Wang Z, Zhang W, Zhao X, Jin C, Li C. Divergent immune roles of two fucolectin isoforms in Apostichopus japonicus. Dev Comp Immunol. 2018;89:1-6.

35. Wang $H$, Xue Z, Liu ZQ, Wang WL, Wang FF, Wang Y, Wang LL, Song LS. A novel C-type lectin from the sea cucumber Apostichopus japonicus (AjCTL2) with preferential binding of D-galactose. Fish Shellfish Immunol. 2018;79: 218-27.
36. Jiang J, Zhou Z, Dong Y, Zhao Z, Sun H, Wang B, Jiang B, Chen Z, Gao S. Comparative expression analysis of immune-related factors in the sea cucumber Apostichopus japonicus. Fish Shellfish Immunol. 2018;72:342-7.

37. Austin $\mathrm{B}$, Zhang $\mathrm{XH}$. Vibrio harveyi: a significant pathogen of marine vertebrates and invertebrates. Lett Appl Microbiol. 2006;43(2):119-24.

38. Aggarwal S, Gurney AL. IL-17: prototype member of an emerging cytokine family. J Leukoc Biol. 2002;71(1):1-8

39. Kolls JK, Linden A. Interleukin-17 family members and inflammation. Immunity. 2004;21(4):467-76

40. Ren $C$, Chen T, Jiang $X$, Wang $Y$, Hu C. Identification and functional characterization of a novel ferritin subunit from the tropical sea cucumber, Stichopus monotuberculatus. Fish Shellfish Immunol. 2014;38(1):265-74.

41. Ren $C$, Chen $T$, Jiang $X$, Luo $X$, Wang $Y$, Hu C. The first echinoderm gammainterferon-inducible lysosomal thiol reductase (GILT) identified from sea cucumber (Stichopus monotuberculatus). Fish Shellfish Immunol. 2015;42(1): 41-9.

42. Grabherr MG, Haas BJ, Yassour M, Levin JZ, Thompson DA, Amit I, Adiconis X, Fan L, Raychowdhury R, Zeng Q, et al. Full-length transcriptome assembly from RNA-Seq data without a reference genome. Nat Biotechnol. 2011;29(7): 644-U130.

43. Pertea G, Huang XQ, Liang F, Antonescu V, Sultana R, Karamycheva S, Lee $Y$, White J, Cheung F, Parvizi B, et al. TIGR gene indices clustering tools (TGICL): a software system for fast clustering of large EST datasets. Bioinformatics. 2003;19(5):651-2.

44. Altschul SF, Gish W, Miller W, Myers EW, Lipman DJ. Basic local alignment search tool. J Mol Biol. 1990;215(3):403-10.

45. Buchfink B, Xie C, Huson DH. Fast and sensitive protein alignment using DIAMOND. Nat Methods. 2015;12(1):59-60.

46. Conesa A, Gotz S, Garcia-Gomez JM, Terol J, Talon M, Robles M. Blast2GO: a universal tool for annotation, visualization and analysis in functional genomics research. Bioinformatics. 2005;21(18):3674-6.

47. Quevillon E, Silventoinen V, Pillai S, Harte N, Mulder N, Apweiler R, Lopez R. InterProScan: protein domains identifier. Nucleic Acids Res. 2005;33:W11620.

48. Langmead B, Salzberg SL. Fast gapped-read alignment with Bowtie 2. Nat Methods. 2012;9(4):357-U354.

49. Li B, Dewey CN. RSEM: accurate transcript quantification from RNA-Seq data with or without a reference genome. BMC Bioinformatics. 2011;12:323.

50. Fog A. Calculation methods for Wallenius' noncentral hypergeometric distribution. Commun Stat Simul Comput. 2008;37(2):258-73.

51. Marwick BBC, Mullen L. Packaging data analytical work reproducibly using $R$ (and friends). PeerJ Preprints. 2018;6:e3192v2.

52. Ihaka R. R: past and future history, vol. 30; 1998.

\section{Publisher's Note}

Springer Nature remains neutral with regard to jurisdictional claims in published maps and institutional affiliations.

Ready to submit your research? Choose BMC and benefit from

- fast, convenient online submission

- thorough peer review by experienced researchers in your field

- rapid publication on acceptance

- support for research data, including large and complex data types

- gold Open Access which fosters wider collaboration and increased citations

- maximum visibility for your research: over $100 \mathrm{M}$ website views per year

At BMC, research is always in progress.

Learn more biomedcentral.com/submissions 